\title{
Павлов В.И. ${ }^{1}$, Пятахин А.М. ${ }^{2}$ \\ Некоторые особенности памяти в управление двигательными действиями в спортивной и профессиональной деятельности \\ ${ }^{1}$ Саратовский государственный медицинский университет имени \\ В.И.Разумовского \\ (Россия, Саратов) \\ ${ }^{2}$ Тамбовский государственный университет имени Г.Р. Державина (Россия, Тамбов)
}

doi: $10.18411 / \mathrm{j}-08-2020-145$

idsp: ljournal-08-2020-145

\section{Аннотация}

Одной из важных сторон педагогической деятельности в вузе для обеспечения полноценной социальной и профессиональной деятельности будущих специалистов является способность использовать методы и инструменты физической культуры и спорта. Целью данного исследования явилось разработка устройства по изучению точности воспроизведения движения. В исследование приняли участие более 1000 респондентов. Было установлено что, регистрируемые изменения в точности воспроизведения параметров заданного движения у студентов, занимающихся по учебной программе физического воспитания в различных учебных отделениях неоднородны.

Ключевые слова: управление двигательными действиями, способность к развитию памяти на движение, воспитание физической культуры.

\section{Abstract}

One of the important aspects of pedagogical activity at the University to ensure the full social and professional activities of future specialists is the ability to use methods and tools of physical culture and sports. The purpose of this study was to develop a device for studying the accuracy of motion reproduction. More than 1000 respondents took part in the survey. It was found that the recorded changes in the accuracy of reproducing the parameters of a given movement in students engaged in the curriculum of physical education in various educational departments are heterogeneous.

Keyword: management of motor actions, the ability to develop memory for movement, physical education.

На основании анализа научной литературы принято считать что, человек должен заблаговременно развивать те физические и психические качества, которые определяют психофизическую надежность и успех в его спортивной и профессиональной деятельности. Под естественным развитием двигательных возможностей понимается процесс их возрастного преобразования в определенных условиях двигательной активности и среды обитания. Эта связь проявляется в необходимости приобретения тех или иных специфических знаний, формирования определенных двигательных умений и навыков, воспитания профессионально важных качеств и свойств личности. В процессе физического воспитания студенческой молодежи остается актуальной проблема дальнейшего развития физических качеств, совершенствования двигательных навыков и приобретения новых двигательных умений [1,2,3].

Двигательные действия и реакции необходимы человеку для общения, через них осуществляется контакт с окружающей средой, они служат внешним проявлением трудовых процессов. Эта связь проявляется в необходимости приобретения тех или иных специфических знаний, воспитания определенных двигательных умений и навыков, и в целом формирования физической культуры личности будущего специалиста. [5]. 
В свете современных представлений о механизмах формирования памяти и регуляции движений, мышцы - не только исполнительный двигательный аппарат, но и своеобразный орган чувств. Движения, которые может выполнять человек, практически бесконечно разнообразны, и каждое из них обусловлено специфическим комплексом мотонейронов. Лишь наиболее простые движения (например, отдергивание конечности или почесывание) осуществляются изолированным спинным мозгом. Все разнообразие двигательных актов, на которые способны мотонейроны и вставочные нейроны спинного мозга, сводится к рефлекторным реакциям. Центральная нервная система (ЦНС) получает информацию о состоянии окружающей среды от рецепторов. Каждый рецептор воспринимает определенный раздражитель - химический, электромагнитный (световые волны), механический или температурный. Рецепторы это датчики, преобразующие энергию раздражителя в электрохимический потенциал. Информация о раздражителе кодируется в виде импульсов в чувствительных (сенсорных) нервах. Эта информация поступает в сенсорные структуры нервной системы, где подвергается декодированию и анализу [4].

Наше исследование было направлено на изучение особенностей двигательной памяти, в процессе физического воспитания будущих медицинских специалистов. Предполагалось решить следующие задачи: разработать и внедрить в педагогическую практику физического воспитания устройство и методику работы с ним по количественному измерению показателей при воспроизведении движений на точность; дать оценку значению способностям человека запоминать, анализировать и управлять мышечно-двигательными ощущениями и действиями при овладении значимыми умениями и навыками в спортивной и профессиональной деятельности.

Методы. В качестве метода исследования использовалась способность человека запоминать, анализировать и воспроизводить пространственно-временные характеристики выполняемого движения. При разработке методики исследования учитывались следующие принципы: информативность, динамичность наблюдения, возможность использования в реальных условиях учебно-тренировочного процесса. Статистическая обработка данных исследования проводилась на персональном компьютере с использованием программы Statistica, с вычислением параметрических и непараметрических критериев различия и коэффициента корреляции показателей. Исследования проводились на базе Саратовского государственного медицинского университета и Тамбовского государственного университета. Под педагогическим наблюдением находились более 1000 респондентов (лицеисты, студенты, интерны, ординаторы и аспиранты основного, специального и спортивного учебных отделений в возрасте 15-25 лет). Для изучения особенностей моторной памяти человека было использовано следующее устройство: линейка со шкалой измерения параметров движения на одной из сторон от 0 до 100 мм влево и от 0 до 100 мм вправо и свободно перемещающимся по ней «бегунком» вправо и влево. Исследования выполнялись группами по три человека. Каждый из них выступал в роли экспериментатора, протоколиста и испытуемого. В работе использовались карандаши и протоколы исследований.

Результаты. В процессе исследования были сопоставлены показатели полученных данных у лиц: с высоким уровнем недельной двигательной активности 1820 часов (группа мастеров спорта, кандидатов в мастера спорта); со средним уровнем недельной двигательной активности 10-12 часов (группа спортсменов первого, второго и третьего разрядов); с низким уровнем двигательной активности 4 часа (группа общей физической подготовки) и 2 часа (факультатив) и менее 2 часов (самостоятельные занятия). Результаты исследования разделялись на шесть групп (I, II, III, IV, V, VI) по уровням функционального состояния моторной памяти и шесть степеней точности воспроизведения движения (ТВД) заданного параметра на измерительной линейки (низкая, ниже средней, средняя, выше средней, высокая, идеальная). Были выявлены 
следующие показатели в управление мышечно-двигательными ощущениями и точностью воспроизведения движения. Средний показатель у лиц (1343), не занимающиеся спортом составил $(19.86 \pm 0.22 *)$. У футболистов (125) составил $(8.86 \pm 1.22 *)$, у борцов (121) составил $(7.09 \pm 0.92 *)$, у шахматистов (126) составил $\left(12.5 \pm 1.40^{*}\right)$, у плавцов (135) составил $(5.28 \pm 0.84 *)$, у легкоатлетов (126) составил $(7.27 \pm 1.60 *)$, у гиревиков (86) составил $(6.61 \pm 0.91 *)$, у баскетболистов (166) составил $(8.40 \pm 0.73 *)$, у лыжников (119) составил $(3.71 \pm 0.62 *)$, у фехтовальщиков (64) составил $(2.70 \pm 0.79 *)$. Выявленные особенности памяти на движение (управление мышечнодвигательными ощущениями, точность воспроизведения движения) у изучаемой категории лиц наглядно показаны ниже в таблице.

\begin{tabular}{|c|c|c|c|}
\hline Оценка & Шкала показателей ТВД & Степень ТВД & Уровень спортивного мастерства \\
\hline & 0 & Эталон & \\
\hline$\ll 5 »$ & $0.1-1.19 \pm 0.47^{*}$ & Высокая & Мастер спорта \\
\hline$\ll 4 »$ & $1.2-5.08 \pm 0.34^{*}$ & Выше средней & 1 разряд; кандидат в мастера спорта \\
\hline$\ll 3 »$ & $5.09-10.6 \pm 0.84^{*}$ & Средняя & 2 разряд \\
\hline «2» & $10.7-19.86 \pm 0.22^{*}$ & Ниже средней & 3 разряд \\
\hline «1» & 19.87 и больше & Низкая & Лица, не занимающиеся спортом \\
\hline
\end{tabular}

* - различия статистически достоверны, $P<0,05$.

В ходе исследования установлено, что мышечно-двигательные ощущения у лиц, занимающихся в различных учебных отделениях вузов неоднородны. При этом корреляционный анализ результатов исследования показал, что способность к управлению движением стоит в одной цепи с мышечным чувством и находится в прямой зависимости от уровня двигательной активности, специализации и уровня спортивного мастерства. На наш взгляд, для совершенствования учебнотренировочного процесса в видах спорта, где результат зависит от точности соревновательных действий, можно использовать физические упражнения на точность выполнения без зрительного контроля, что позволит максимально совершенствовать мышечное чувство и развивать моторную память.

\section{Выводы:}

1. Регистрируемые изменения в точности воспроизведения параметров заданного движения у лиц, занимающихся в процессе физического воспитания в различных учебных отделениях вузов, неоднородны.

2. Корреляционный анализ показал, что память на движение у студентов спортсменов стоит в одной цепи с мышечным чувством и находится в прямой зависимости от вида спортивной специализации, уровня квалификации и спортивного мастерства.

3. Проведенное исследование дало возможность определить ведущие и нейтральные виды спорта для обеспечения полноценной социальной и профессиональной деятельности будущего специалиста.

4. Анализ результатов исследования позволил составить пособие «Моторная память и двигательные действия человека», которое было рекомендовано учебно-методическим объединением по медицинскому и фармацевтическому образованию вузов России в качестве учебного пособия для студентов медицинских вузов.

$$
* * *
$$

1. Ильинич, В.И. Физическая культура студента и жизнь: Учебник. - М.: Гардарики, 2007. - 366с.

2. Кряжев, В.Д. Двигательные возможности человека: методологические аспекты развития, сохранения и восстановления /В.Д. Кряжев //Теория и практика физической культуры. - 2003. №1. - C. 58-61. 
3. Мусина, С.В. Поиск путей повышения эффективности учебного процесса по физической культуре в вузах: физическая культура и спорт в 21 веке /С.В. Мусина, Е.В. Егорычева: Сб. науч. тр. Волжский, - 2006. - С. $238-240$.

4. Дубровский, В.И., Федорова В.Н. Биомеханика: Учеб. для сред.и высш. учеб. заведений /В.И. Дубровский. - М.: Изд-во ВЛАДОС-ПРЕСС, 2003. - С.304.

5. Павлов В.И. Исследование моторной памяти в процессе формирования профессиональноприкладной физической культуры личности врача /В.И. Павлов //Саратовский научномедицинский журнал. 2011. Т.7, № 3. - С. 730-734.

\section{Патрикеев А.В. \\ Изучение темы «Периодический вибрационный контроль зданий и сооружений» при дистанционной форме обучения студентов строительных специальностей}

ВГАОУ ВО «Российский университет транспорта» (Россия, Москва)

doi: $10.18411 / \mathrm{lj}-08-2020-146$

idsp: ljournal-08-2020-146

\section{Аннотация}

Рассмотрены вопросы изучения студентами строительных специальностей периодического вибрационного контроля зданий и сооружений в форме выполнения курсовой (контрольной) работы при дистанционной форме обучения. При этом исходные материалы реальных динамических архивов в текстовом формате подвергаются спектральному анализу с использованием стандартного офисного пакета Microsoft Excel.

Ключевые слова. Инженерное сооружение, периодический вибрационный контроль, частота колебаний, логарифмический декремент затухания, дистанционная форма обучения, анализ данных, Microsoft Excel.

\section{Abstract}

The issues of studying by students of construction specialties of periodic vibration control of buildings and structures in the form of coursework (control) work in distance learning are considered. At the same time, the source materials of real dynamic archives in text format are subjected to spectral analysis using a standard office suite Microsoft Excel.

Keywords Engineering structure, periodic vibration control, vibration frequency, logarithmic damping decrement, distance learning, data analysis, Microsoft Excel.

При составлении Паспорта инженерного сооружения, в соответствии с ГОСТ 31937-2011, требуется внесение сведений о частотах и декрементах затухания колебаний данного сооружения по взаимно перпендикулярным осям. Периодический контроль (мониторинг) основных динамических характеристик является простым и удобным способом экспресс-оценки категории технического состояния. Такой контроль оказывается важным для оценки технической безопасности в процессе эксплуатации сооружения, поскольку зафиксированное существенное изменение этих характеристик может свидетельствовать о приближении состояния несущих конструкций к аварийному, что необходимо влечет за собой принятие решения о возможности его дальнейшей эксплуатации. Таким образом, динамический контроль сооружения повышает общий уровень безопасности в процессе эксплуатации сооружения.

Как правило, наибольший интерес при динамическом мониторинге (периодическом контроле собственных частот колебаний сооружения и их декрементов затухания) представляет контроль колебаний первого тона, обладающих наибольшей энергией. Контроль может выполняться путём регистрации электронных архивов колебаний характерных точек конструкции сооружения, с последующей 